\title{
Regional Climate Simulation for Arizona: Impact of Resolution on Precipitation
}

\author{
Ashish Sharma and Huei-Ping Huang \\ School for Engineering of Matter, Transport and Energy, Arizona State University, Tempe, AZ 85287, USA \\ Correspondence should be addressed to Ashish Sharma, ashish.sharma.1@asu.edu
}

Received 10 January 2012; Revised 14 March 2012; Accepted 31 March 2012

Academic Editor: Hann-Ming Henry Juang

Copyright () 2012 A. Sharma and H.-P. Huang. This is an open access article distributed under the Creative Commons Attribution License, which permits unrestricted use, distribution, and reproduction in any medium, provided the original work is properly cited.

This study performs regional climate simulations for Arizona, a region with complicated terrain. The dependence of simulated rainfall on model resolution is explore by climate downscaling experiments using the Weather Research and Forecasting model. The model's horizontal resolution was refined from 12 to 6 , then to $3 \mathrm{~km}$. The total rainfall for winter and for different subdomains of Arizona is found to increase substantially with the refinement from 12 to $6 \mathrm{~km}$ grid. A further refinement to $3 \mathrm{~km}$ leads to a smaller change in rainfall, indicating numerical convergence at that scale. Comparisons with observations revealed that the 6 and $3 \mathrm{~km}$ runs produced excessive rainfall for winter while the $12 \mathrm{~km}$ simulations are closer to observation. This implies that the parameterization schemes for rainfall are not resolution independent, thus a refinement of resolution does not guarantee better results. It cautions against hastily pushing for increasingly higher resolution in practical downscaling simulations. An analysis of the simulated hourly rainfall shows that the $3 \mathrm{~km}$ runs produce significantly more extreme rainfall events than the $12 \mathrm{~km}$ runs. The 6 and $3 \mathrm{~km}$ runs also produced more complicated spatial patterns of seasonal rainfall and vertical velocity, reflecting the influence of fine-scale topography.

\section{Introduction}

Global climate models used for seasonal and long-term prediction have typically a coarse resolution of $O(100 \mathrm{~km})$. At that resolution, most of the rainfall is produced by subgrid-scale convective parameterization with a very crude representation of surface heterogeneity within a grid box. While those models have produced meaningful projections of large-scale hydrological conditions in future climate (e.g., $[1,2])$, they do not have the capacity to predict local climate changes at the mesoscale especially for regions characterized by complicated terrain. A complementary approach of climate downscaling has been developed that uses largescale boundary conditions to constrain a mesoscale model for long-term, regional climate prediction (e.g., [3-5]). The increased model resolution allows an increase in the fraction of grid-scale precipitation and reduction of parameterized subgrid precipitation. This, combined with a refined representation of topography and surface heterogeneity, might help improve the realism of simulated precipitation (e.g.,
[4, 6-9]). State-of-the-art climate downscaling studies for seasonal and longer time scales have so far adopted a horizontal resolution within the range of $12-50 \mathrm{~km}$ (e.g., [915]). On the other hand, previous studies that adopted a higher resolution (e.g., $3 \mathrm{~km}$ ) to determine the sensitivity of rainfall on model resolution and convective parameterization are mostly restricted to short-term weather prediction (e.g., $[16,17])$. To bridge this gap of knowledge, this study will explore the changes in rainfall in seasonal climate downscaling simulations when the horizontal resolution of the regional model is refined from $12 \mathrm{~km}$ to $3 \mathrm{~km}$. As will be demonstrated shortly, grid-scale precipitation becomes the dominant contributor to the total rainfall at these scales. Given so, we will also test the sensitivity of simulated rainfall to the switching on and off of cumulus parameterization. The main purpose of our key simulations is twofold. First, we will determine how and whether the seasonal mean rainfall converges numerically when the resolution of the model is successively refined to the nearly cloud-resolving scale of $3 \mathrm{~km}$. Second, if a numerical converge does occur, we should 

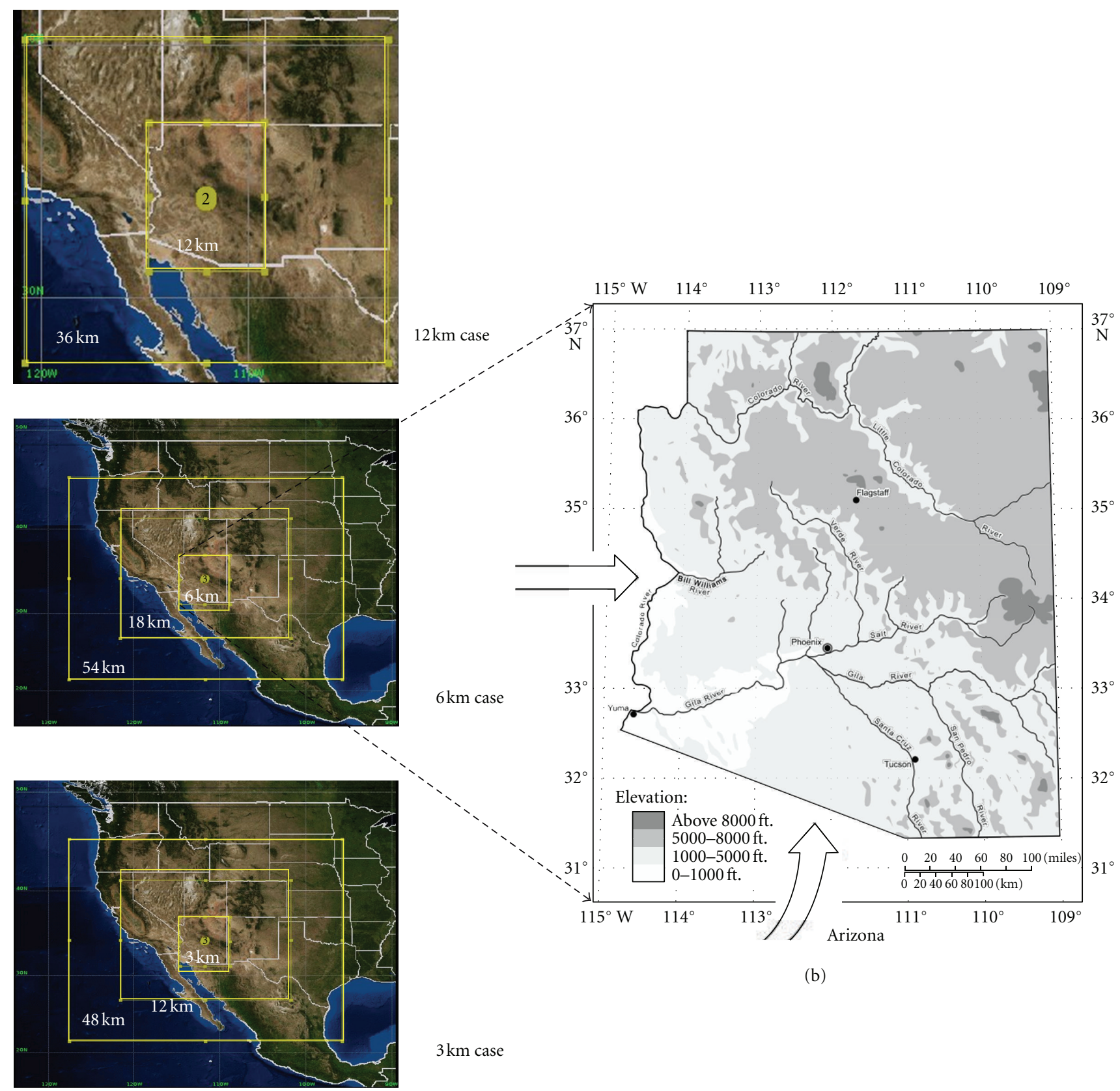

(b)

(a)

FIgURE 1: The model domains and arrangement of nesting for the numerical experiments: (a) nested domains for WRF model and (b) an illustration that the innermost domain covers the State of Arizona. The arrows indicate the prevailing directions of moisture fluxes into Arizona in wintertime [18]. The topographic map is taken from Arizona Geographic Alliance, Arizona State University (http://geoalliance.asu.edu/azga/).

examine whether the solution converges to the observed seasonal mean climatology.

We choose to perform the numerical simulations for the winter season in Arizona, a region with dramatic contrasts in topography and local rainfall patterns [18-20] that provide an ideal test ground for the impact of model resolution. We choose winter because numerical models, whether global or regional, are widely known to produce substantial biases in North American summer monsoon (e.g., [21, 22]), while their performance for wintertime precipitation is generally more robust. While the summertime bias is itself an important issue, it might prove to be a distraction in the context of our sensitivity study. Regional climate simulations using the Weather Research and Forecast (WRF) model [23] will be performed over seven winter (November-January) seasons. The dependence of the climatology as well as highfrequency behavior of simulated rainfall on model resolution and/or subgrid-scale convective scheme will be analyzed. 


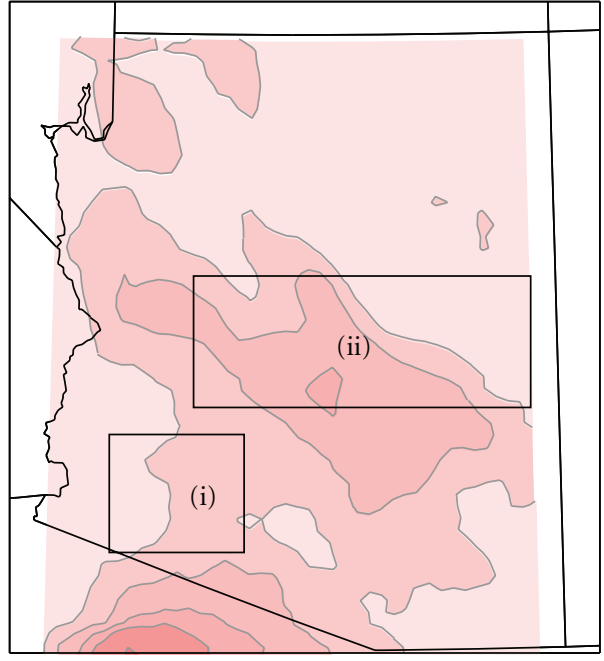

(a)

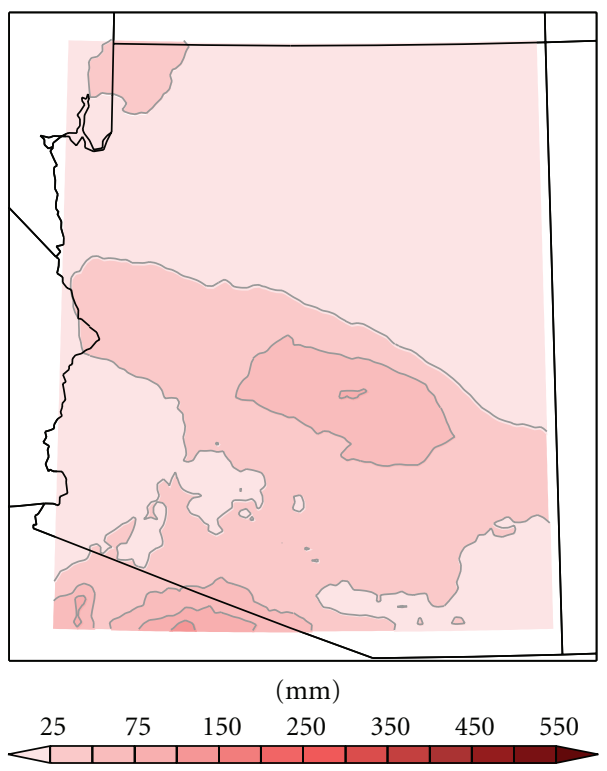

(c)

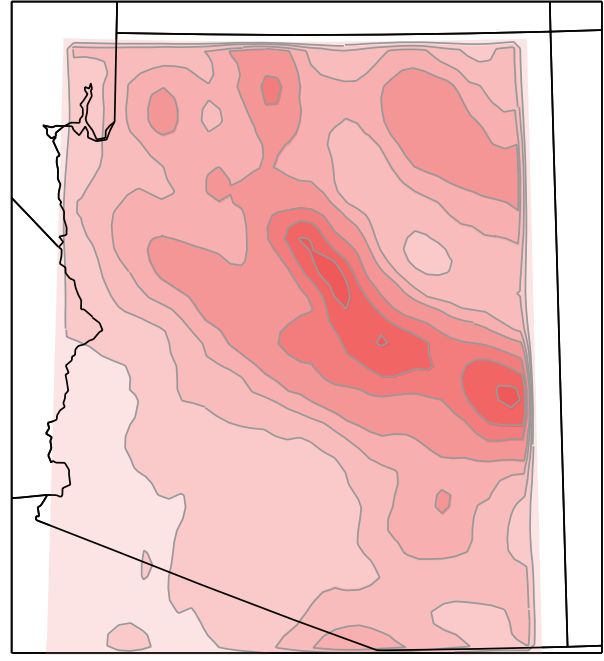

(b)

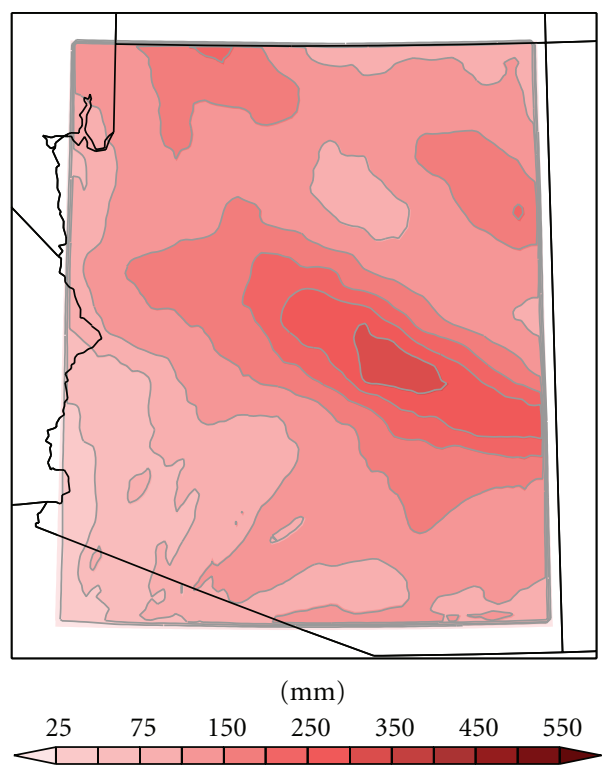

(d)

FIGURE 2: The cumulative rainfall for winter season (November 1-January 31), averaged over 7 winters from 2003 to 2009 , from different sets of runs. (a) Rainfall produced by subgrid-scale cumulus parameterization (RAINC) from the $12 \mathrm{~km}$ runs. (b) Rainfall produced by grid-scale convection (RAINNC) from the $12 \mathrm{~km}$ runs. (c) RAINC from the $6 \mathrm{~km}$ runs with cumulus parameterization turned on (d) RAINNC from the $6 \mathrm{~km}$ runs with cumulus parameterization turned on. Boxes (i) and (ii) in (a) are the areas chosen for the further analysis of the timeseries of rainfall in Figures 5-7. Box (i) is defined as $111.78^{\circ} \mathrm{W}-113.61^{\circ} \mathrm{W}$ and $31.90^{\circ} \mathrm{N}-33.69^{\circ} \mathrm{N}$ and box (ii) is defined as $109.35-112.02^{\circ} \mathrm{W}$ and $33.25^{\circ} \mathrm{N}-35.18^{\circ} \mathrm{N}$. The plot shows the whole innermost domain, including the sponge layer for nesting.

To maintain focus, the analysis will focus on liquid-form precipitation, leaving the complexity of snowfall to later work.

\section{Model and Numerical Experiments}

We will use Weather Research and Forecast (WRF) [23] Model Version 3.1, a nonhydrostatic mesoscale model that allows multiple nesting. The model grids are configured such that the innermost domain covers the State of Arizona while the outermost domain covers the entire western USA (see Figure 1). In between, two- or three-layer nesting is adopted with the large-scale boundary condition imposed at the lateral boundary of the outermost domain only. We will not apply interior nudging. The time-varying large-scale boundary condition is constructed from 6-hourly NCEP Global Analysis (FNL) data (from the NCAR CISL Data Support Section archive, http://dss.ucar.edu/datasets/ds083.2/) on 1 deg $\times 1$ deg grid. Hourly outputs are saved for all runs to help the analysis of high-frequency behavior and extreme events of rainfall.

The horizontal grid size for the innermost domain is varied from $12 \mathrm{~km}$ to $6 \mathrm{~km}$, then to $3 \mathrm{~km}$. Hereafter, unless 
TABLE 1: A summary of the horizontal resolution and arrangement of nesting for four sets of simulations performed in this study. Also indicated in the table is whether cumulus parameterization is turned on or off.

\begin{tabular}{|c|c|c|c|c|}
\hline \multirow[b]{2}{*}{ Nesting } & \multicolumn{3}{|c|}{ Resolution } & \multirow{2}{*}{$\begin{array}{l}\text { Cumulus convective } \\
\text { parameterization } \\
\text { (Kain-Frisch scheme) }\end{array}$} \\
\hline & $\begin{array}{c}\text { Outermost } \\
\text { domain }\end{array}$ & $\begin{array}{c}\text { Intermediate } \\
\text { domain }\end{array}$ & $\begin{array}{l}\text { Innermost } \\
\text { domain }\end{array}$ & \\
\hline 2 layer & $36 \mathrm{~km}$ & - & $12 \mathrm{~km}$ & On \\
\hline \multirow{2}{*}{3 layer } & & & & On \\
\hline & $54 \mathrm{~km}$ & $18 \mathrm{~km}$ & $6 \mathrm{~km}$ & Off \\
\hline 3 layer & $48 \mathrm{~km}$ & $12 \mathrm{~km}$ & $3 \mathrm{~km}$ & Off \\
\hline
\end{tabular}

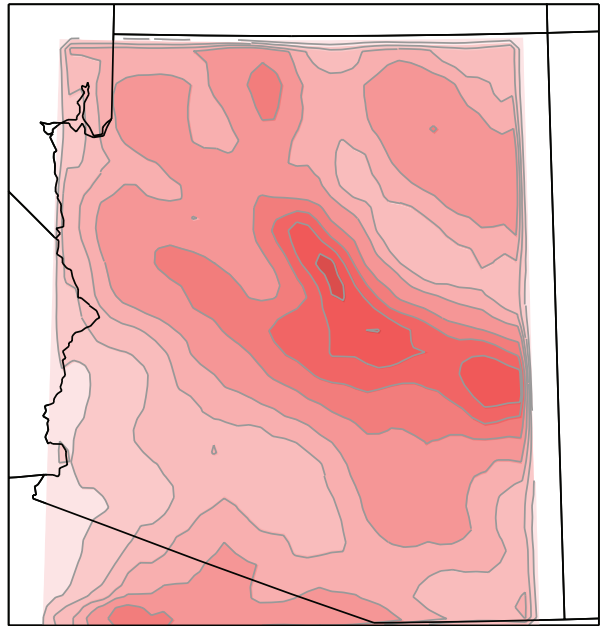

(a)

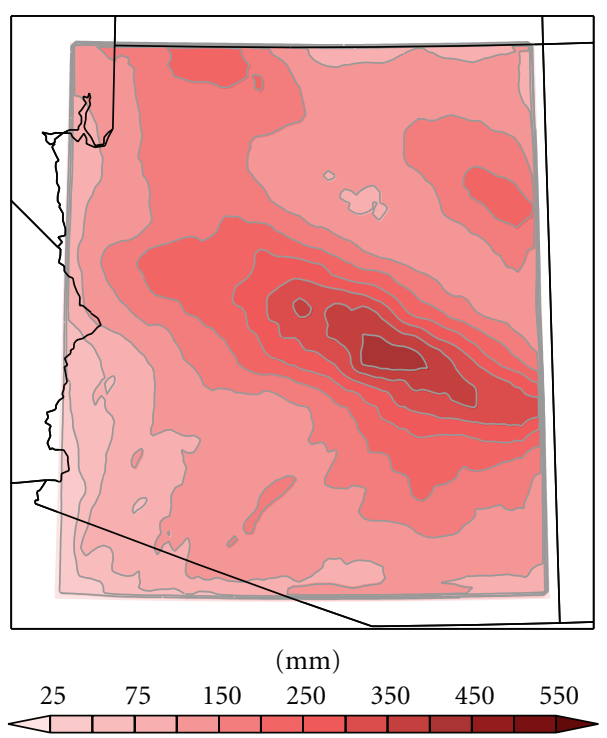

(c)

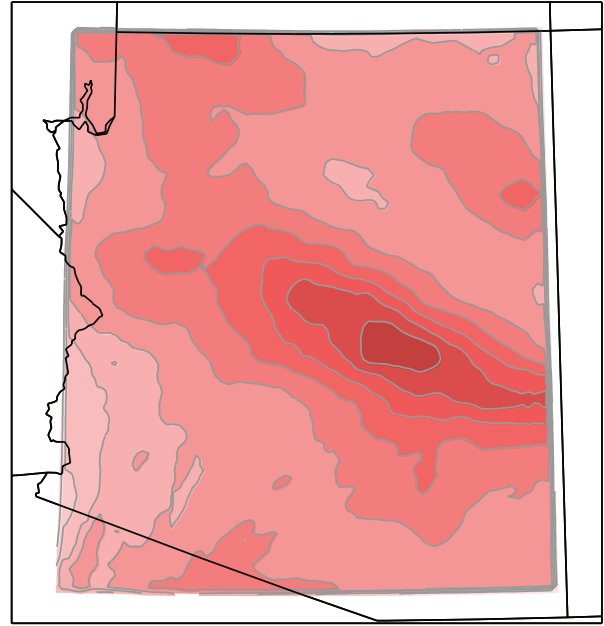

(b)

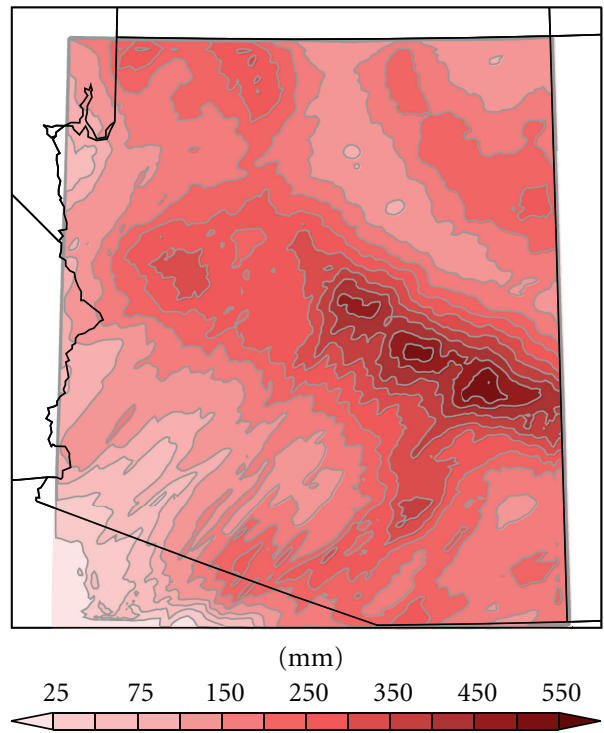

(d)

FIgURE 3: Same as Figure 2 but for different runs or combinations of variables for rainfall. (a) Total rainfall (RAINC+RAINNC) from the $12 \mathrm{~km}$ runs. (b) Total rainfall (RAINC+RAINNC) from the $6 \mathrm{~km}$ runs with cumulus parameterization turned on. (c) Total rainfall (all produced by grid-scale convection, RAINNC) from the $6 \mathrm{~km}$ runs with cumulus parameterization turned off. (d) Total rainfall (RAINNC) from the $3 \mathrm{~km}$ runs. 


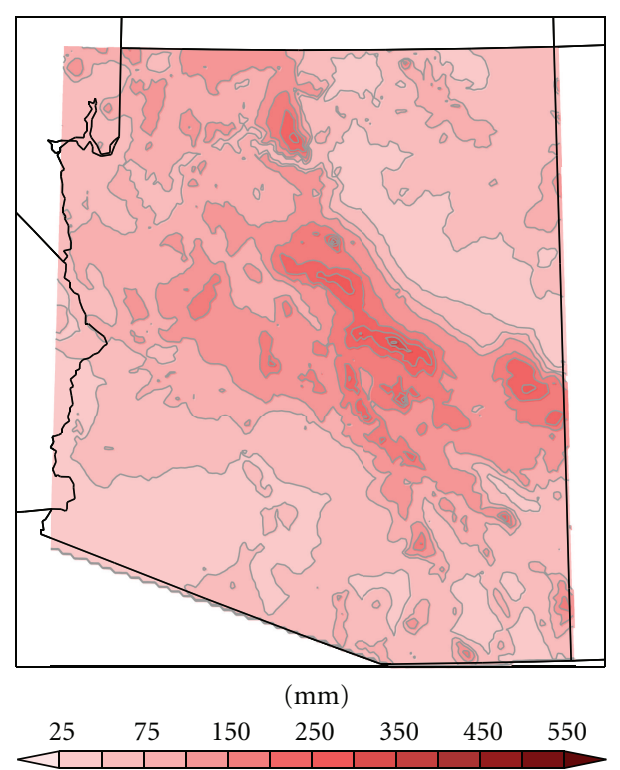

FIgURE 4: The cumulative observed rainfall for winter season (November 1-January 31), averaged over 7 winters from 2003 to 2009, using the PRISM monthly data.

otherwise noted, the model resolution in our discussion refers to the grid size of the innermost domain. The $12 \mathrm{~km}$ runs are carried out with two layers of nesting, using $36 \mathrm{~km}$ resolution for the outer domain. The $6 \mathrm{~km}$ and $3 \mathrm{~km}$ runs adopt a 3-layer nesting using $(54 \mathrm{~km}, 18 \mathrm{~km})$ and $(48 \mathrm{~km}$, $12 \mathrm{~km}$ ) as the resolutions for the outermost and intermediate domains, respectively. Detail of the nesting is shown in Figure 1. At $12 \mathrm{~km}$ resolution, subgrid-scale cumulus convective scheme is turned on. As the parameterized convective rainfall diminishes with an increasing resolution, at $6 \mathrm{~km}$ resolution we perform a pair of experiments, one with convective scheme turned on and another with it turned off. (This is for the innermost domain only. Cumulus parameterization is always turned on for the intermediate and outermost domains.) Convective scheme is turned off at $3 \mathrm{~km}$ resolution. Whenever convective parameterization is retained, we choose Kain-Frisch scheme [24]. Table 1 summarizes the horizontal resolution and arrangement of nesting for our major experiments. For the two cases in Table 1 that eliminate cumulus convective parameterization, all rainfall is produced by grid-scale processes.

To ensure proper resolution of topography and surface characteristics that matches the increase in model resolution, we use USGS 24 classification categories of land-use data for interpolating topography and land surface characteristics (from standard geogrid package in WRF) at different spatial resolutions for different levels of nesting: we do not smooth the topography but use $10^{\prime}, 5^{\prime}$, and $2^{\prime}$ geogrid resolution for the outermost, intermediate, and innermost model domains, respectively. (The model automatically interpolates these topographic data to the model grids.) Since $2^{\prime}$ is comparable with the highest model resolution ( $3 \mathrm{~km}$ grid) used in this study, this means that the successive refinement of the model resolution does lead to finer representation of the topography. The model has 28 levels in the vertical with the model top set at $50 \mathrm{hPa}$. For other physical parameterization schemes, we selected (from WRF's available options) singlemoment (WSM) 3-class simple ice scheme for microphysics, Dudhia scheme for shortwave and rapid radiative transfer model (RRTM) scheme for longwave radiation, and MoninObukhov similarity scheme for surface-layer process. The Yonsei University (YSU) scheme is used for boundary layer mixing and thermal diffusion is chosen for land surface process.

Each of the 4 cases in Table 1 consists of seven 92day continuous runs for the 7 winter seasons (NovemberJanuary) from 2003 to 2009. (Winter 2009 refers to November 2009-January 2010.) Sea surface temperature is updated daily and is provided from FNL data. As explained in Section 1, winter is chosen because the model generally simulates the climatology of the cold season more accurately than the warm season. Note that for water resource applications, wintertime rainfall is particularly important over the semiarid part of Arizona, where rainfall in summer is quickly recycled back to the atmosphere due to intense evaporation (e.g., [25]).

To compare the WRF simulations of winter seasonal rainfall with observation, we will use the Parameter-elevation Regressions on Independent Slopes Model, data archive available at http://www.prism.oregonstate.edu/ (PRISM) monthly mean precipitation dataset. It is consolidated from station measurements with spatiotemporal interpolations $[26,27]$ and is the official climatological rainfall data of USDA.

\section{Results}

3.1. Seasonal Cumulative Rainfall. We first analyze the simulated rainfall based on two variables, RAINC and RAINNC, from the WRF model output. The former is the rainfall produced by cumulus parameterization and the latter is the rainfall produced by grid-scale processes, including mechanical lifting and adjustment of thermodynamic profile at grid scale. Figures 2(a) and 2(b) show the seven-winter mean of November-January cumulative rainfall produced by parameterized subgrid-scale convection and grid-scale processes, respectively, from the $12 \mathrm{~km}$ run. At this resolution, grid-scale rainfall is already the dominant contributor to the total rainfall, in comparison to coarse resolution global climate models for which the precipitation generated by subgrid-scale convective scheme is comparable to gridscale precipitation. The maximum of rainfall over central Arizona (along the Mogollon Mountains) in both panels reflects topographic influence. A maximum of rainfall just south of US Mexican border (at the bottom edge of the plot) in Figure 2(a) is due to the fact that that particular spot is over the water (Gulf of California). Note that in this study we do not analyze snowfall, which is otherwise substantial over areas with high altitude in northern Arizona.

Figures 2(c) and 2(d) are similar to Figures 2(a) and 2(b) but for the simulations with $6 \mathrm{~km}$ resolution that 

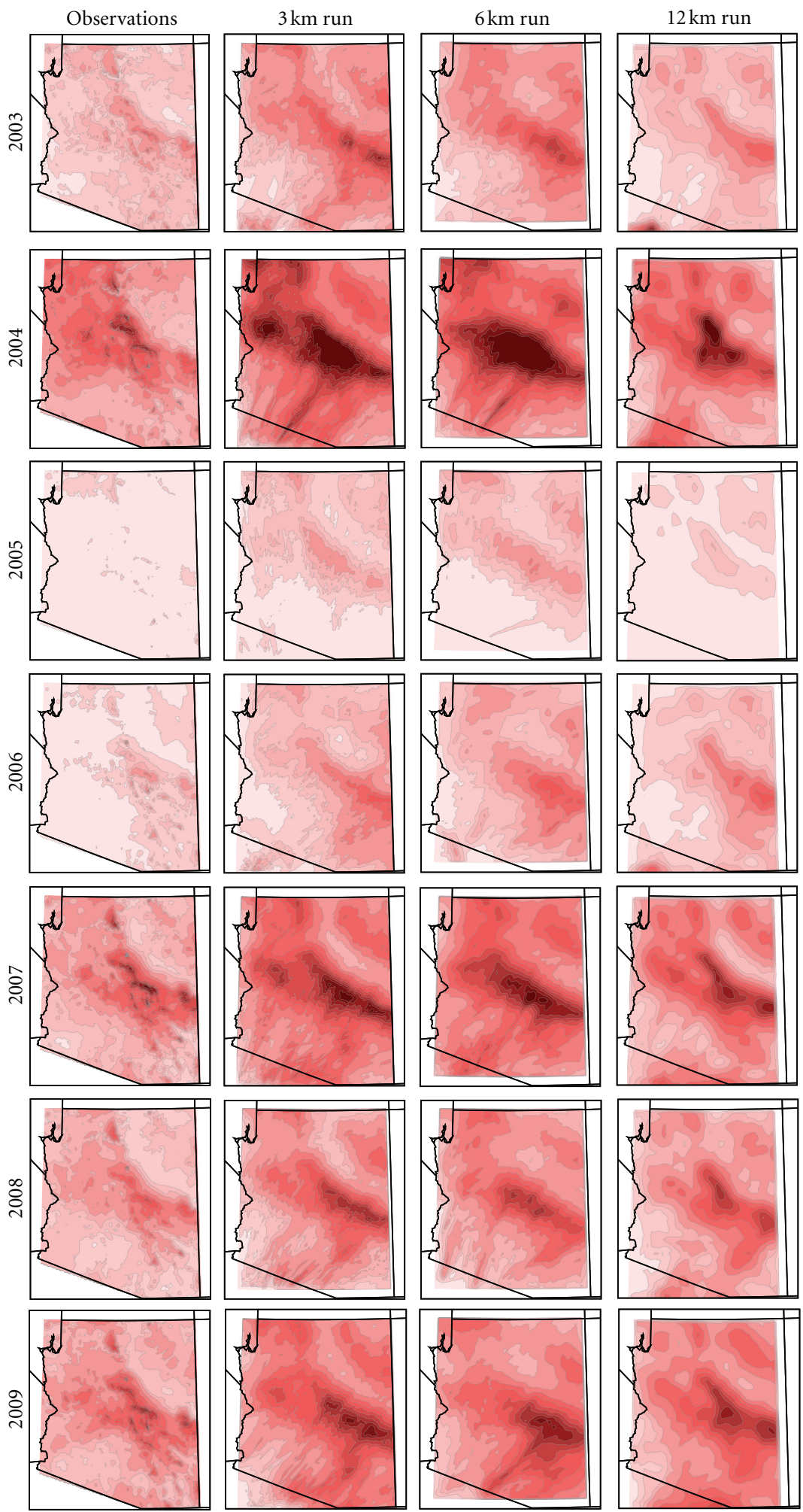

(mm)

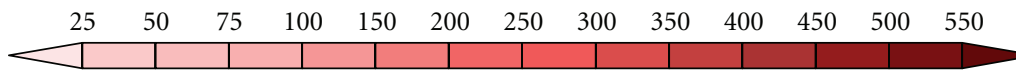

FIGURE 5: A year-by-year comparison of the simulated winter seasonal-mean rainfall with observation using the PRISM dataset. The 7 winters are arranged from top to bottom. The observation is shown at the leftmost column, followed to the right by the simulations with $3 \mathrm{~km}, 6 \mathrm{~km}$, and $12 \mathrm{~km}$ resolution. For brevity, for the $6 \mathrm{~km}$ runs only the case with cumulus convective scheme turned off is shown. The results for the case with convective scheme turned on are similar in pattern and magnitude. 


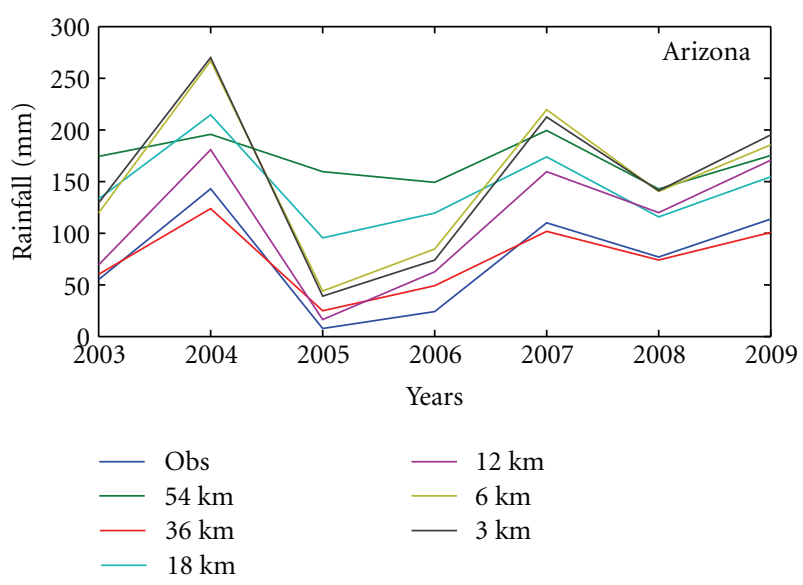

(a)

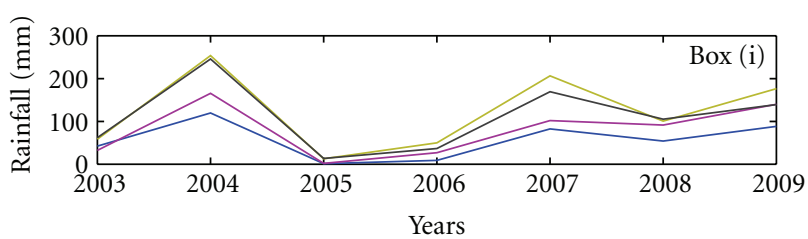

(b)
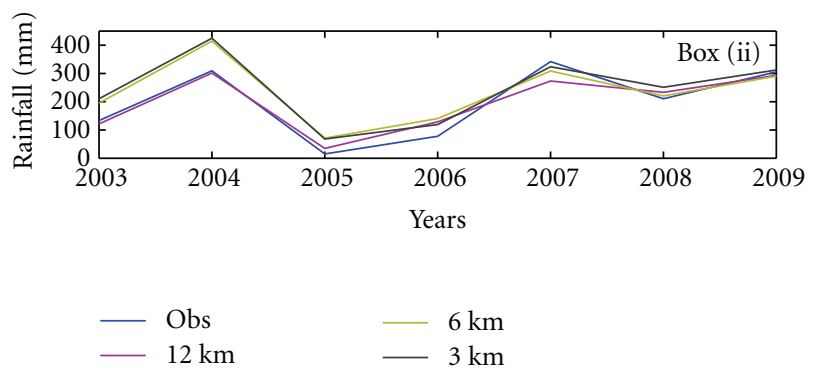

(c)

Figure 6: Comparisons of the simulated winter seasonal mean rainfall with observation. Shown are the averages over (a) the entire innermost model domain that covers the State of Arizona, (b) box (i), and (c) box (ii) (as marked in Figure 2(a)). The observation from PRISM data is in dark blue. The cases for the simulations are labeled in the legends. See text for detail.

retained cumulus convective parameterization. The refinement of resolution from 12 to $6 \mathrm{~km}$ leads to a further decrease of the relative contribution of the subgrid-scale convective rainfall as expected. Interestingly, the total rainfall (RAINC+RAINNC) increases with resolution, as further shown in Figures 3(a) (total rainfall at $12 \mathrm{~km}$ resolution) and 3 (b) $(6 \mathrm{~km}$ resolution). This increase occurs not only over the central mountain range of Arizona but also over southern Arizona where the mountains are shorter and more scattered, and with smaller scales (therefore the increased resolution leads to an enhanced effects of those mountains on rainfall).

Given the diminished contribution of parameterized subgrid-scale convection to the total rainfall at $6 \mathrm{~km}$ resolution, we next experiment with an identical set of runs but with cumulus convective scheme turned off. The total winter seasonal rainfall (that comes entirely from RAINNC) for this run is shown in Figure 3(c). It is found that eliminating the convective parameterization only very slightly affects the total rainfall. (The case with RAIN $\mathrm{C}=0$ produced even a slightly greater amount of total rainfall.) Without cumulus parameterization, grid-scale rainfall (RAINNC) was enhanced to compensate for the absence of subgrid-scale convection. This behavior is qualitatively understandable since, given the large-scale moisture convergence, a certain amount of rainfall is anticipated in order to restore static stability and maintain water balance. Without cumulus parameterization, grid-scale processes do all the work to produce this amount of rainfall.

With the insight from the two sets of $6 \mathrm{~km}$ runs, we then executed the $3 \mathrm{~km}$ runs without cumulus parameterization. Figure 3(d) shows the total winter rainfall from this set of runs. The increase of horizontal resolution from 6 to $3 \mathrm{~km}$ leads to a relatively smaller change in the total rainfall for Arizona, compared to the change from 12 to $6 \mathrm{~km}$ (this will be quantified in the discussion related to Figure 5). The $3 \mathrm{~km}$ run does produce a few spots of intense rainfall over the mountain range in central Arizona that are not as pronounced in the $6 \mathrm{~km}$ runs. In addition, at $3 \mathrm{~km}$ resolution one begins to see northwest-southeast-oriented streaks in the rainfall pattern, which likely reflect the effects of the fine-scale topography in that region. The substantial increase in regional rainfall from 12 to $6 \mathrm{~km}$ cases underscores the sensitivity of seasonal rainfall simulation to model resolution. From 6 to $3 \mathrm{~km}$ the simulated rainfall begins to convergence (as will be more clearly demonstrated in Figure 5). We should next examine whether they converge to the observed climatology.

3.2. Comparison of Simulated Rainfall with Observations. Figure 4 shows the seven-year average of the winter (November-January) cumulative rainfall from observation that can be used to compare to the model simulations in Figures 2-3. Figure 5 further compares the simulated yearto-year winter seasonal rainfall at different model resolutions with the corresponding observations. The observations are based on the PRISM dataset [26, 27] of monthly mean rainfall. They are shown in Figure 5 in the leftmost column. The other 3 columns show the simulations with 12, 6, and $3 \mathrm{~km}$ resolutions. (For brevity, for the $6 \mathrm{~km}$ runs we only show the case with cumulus convective scheme turned off.) This comparison reveals several interesting behaviors of the simulated rainfall. First, the model simulations (at all resolutions) did qualitatively capture the interannual variability of rainfall over Arizona. For example, the model produced a very wet winter for 2004 and a dry winter for 2005 as observed. This is further illustrated in Figure 6, the comparison of the year-to-year domain averaged rainfall with observation (PRISM data) for (a) the entire Arizona, (b) box (i), and (c) box (ii) (the two boxes are marked in Figure 2(a)). In Figure 6(a), we have also added the rainfall from coarser resolution runs with 54,36 , and $18 \mathrm{~km}$ grids, taken from the outermost or intermediate domains for the major simulations. They are not included in the plots for box (i) and box (ii) because with the coarse resolution the 


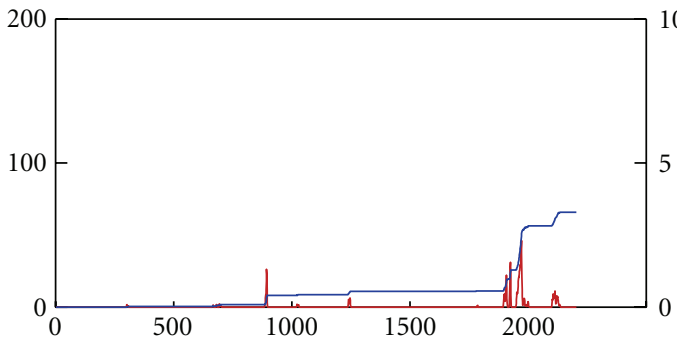

(a)

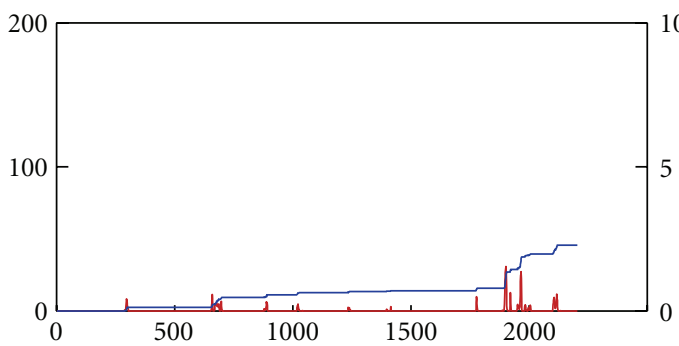

(c)

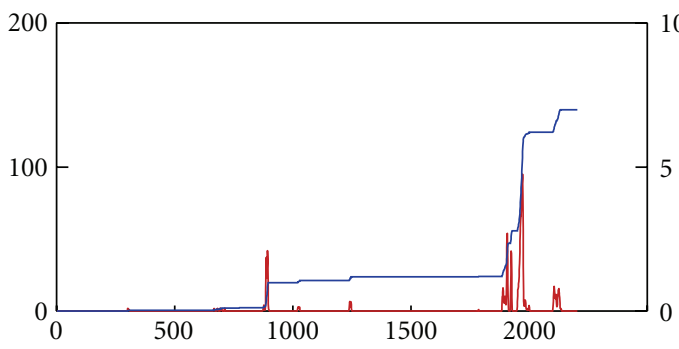

(e)

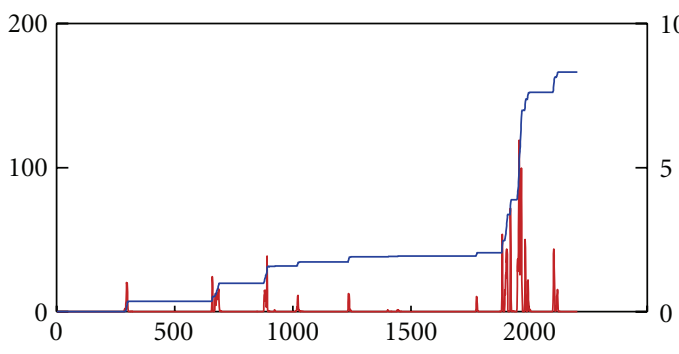

(g)

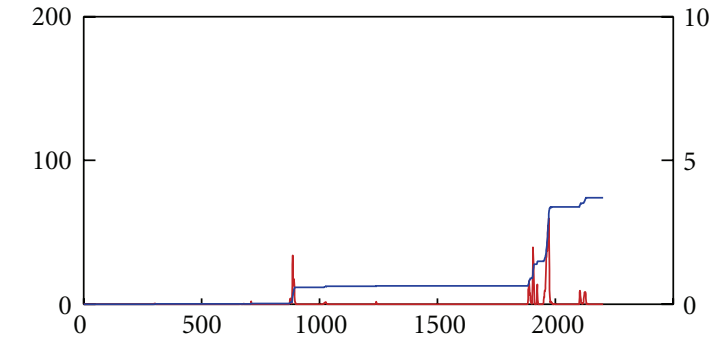

(b)

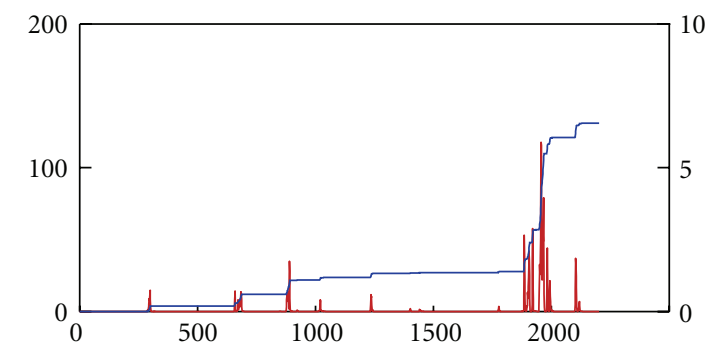

(d)

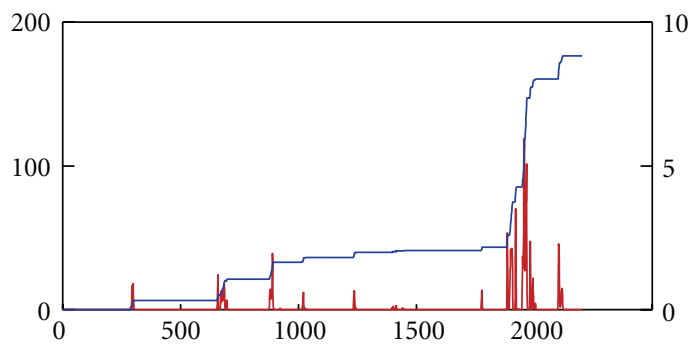

(f)

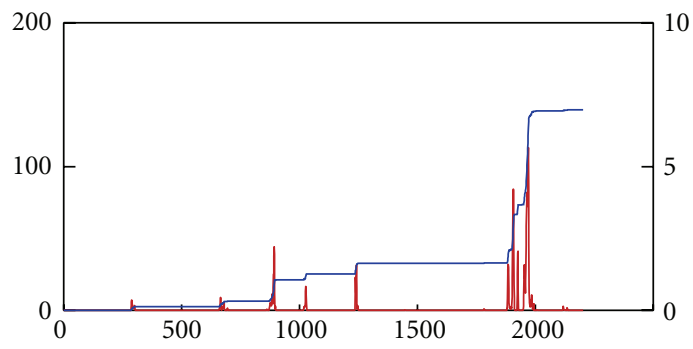

(h)

FIgURE 7: Time-series of hourly rainfall averaged over box (i) in Figure 2(a) for 1 November 2009-31 January 2010 for different sets of runs. Red and blue curves are the instantaneous and cumulative rainfall, respectively. The top 4 panels correspond, in the same order, to the 4 panels shown in Figure 2 (panel a in Figure 6 corresponds to panel a in Figure 2, etc.). The bottom 4 panels correspond to the 4 panels in Figure 3 (panel (e) in Figure 6 corresponds to panel (a) in Figure 3, etc.) The scale at left, in mm, is for the cumulative rainfall and scale at right, in $\mathrm{mm} / \mathrm{hr}$, is for the instantaneous rainfall. Abscissa is time in hours since 00Z, 1 November 2009.

number of grid points within each box is relatively small, rendering the statistics less reliable. Except for the case with the lowest resolution $(54 \mathrm{~km})$, all other simulations capture a significant portion of the observed interannual variability of rainfall. The more notable difference among those runs is actually in the long-term mean, for which the $36 \mathrm{~km}$ case matches well with observation while the runs with higher resolutions produce excessive rainfall. A plausible explanation is that $36 \mathrm{~km}$ is close to the resolution used by the majority of applications of WRF and likely the resolution used for model validation during the development phase of the model. If the model was previously tuned at around $30 \mathrm{~km}$ resolution for its climatology to resemble observation, there is indeed no guarantee that refining (or coarsening, as is the case of $54 \mathrm{~km}$ run) the resolution will improve or maintain the simulated climatology. That Figure 6 shows otherwise is an indication that the physical parameterization schemes in the model are not resolution 


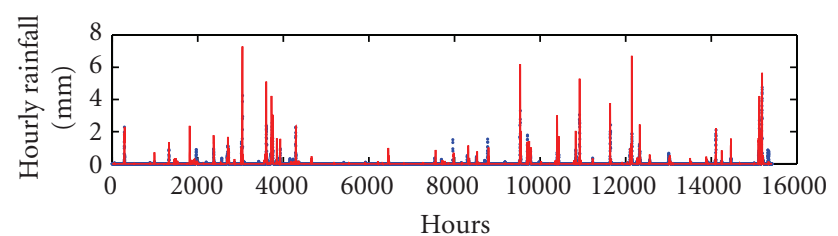

(a)

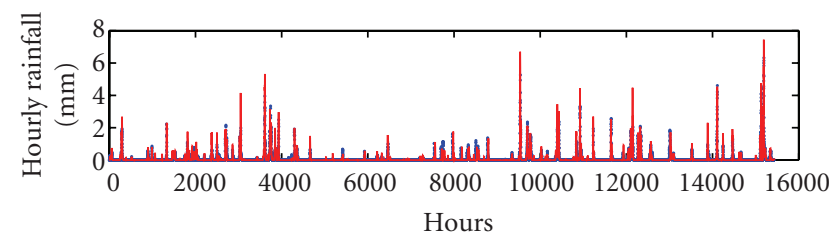

(b)

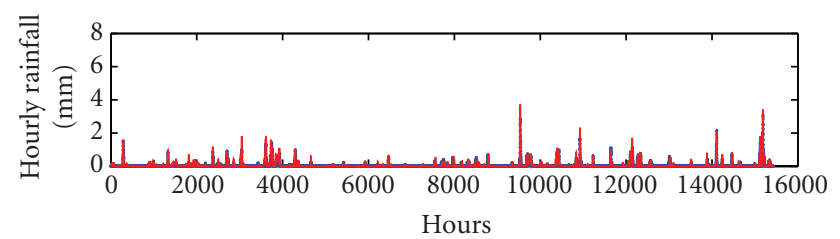

- $12 \mathrm{~km}$

$-3 \mathrm{~km}$

(c)

FIGURE 8: Time series of hourly rainfall averaged over (a) box (i), (b) box (ii) in Figure 2(a), and (c) the entire innermost domain (Arizona). The red line and blue dots are for the $3 \mathrm{~km}$ and $12 \mathrm{~km}$ runs, respectively. Each panel contains the time series for all 7 winters stitched together. Abscissa is time in hours.

dependent. As surveyed in Introduction, most of the existing climate downscaling experiments have used a horizontal resolution coarser than $12 \mathrm{~km}$. Given our finding, those appear to be sensible choices. We caution against hastily pushing for increasingly higher resolutions without carefully validating the model climatology at those resolutions.

An encouraging aspect of Figure 6 is that it shows the merit of using WRF to simulate interannual variability of rainfall (even without interior nudging, as is the case of our simulations) in the context of climate downscaling. This conclusion is slightly more optimistic than some recent studies ([11] and discussions therein) that voiced concerns that the amplitude of interannual variability is reduced in climate downscaling especially if the regional model domain is large and interior nudging is turned off. However, this study has used a smaller model domain and a higher horizontal resolution than those adopted by Rockel et al. [11] and related studies. Thus, the finding here is still consistent with the view of Rockel et al. that using a smaller domain helps alleviate the problem of the loss of low-frequency variability.

\subsection{Temporal Characteristics of Rainfall and Extreme Events.} Figure 7 shows the model-simulated hourly rainfall for one of the winters, November 2009-January 2010, for a subdomain over southern Arizona marked as box (i) in

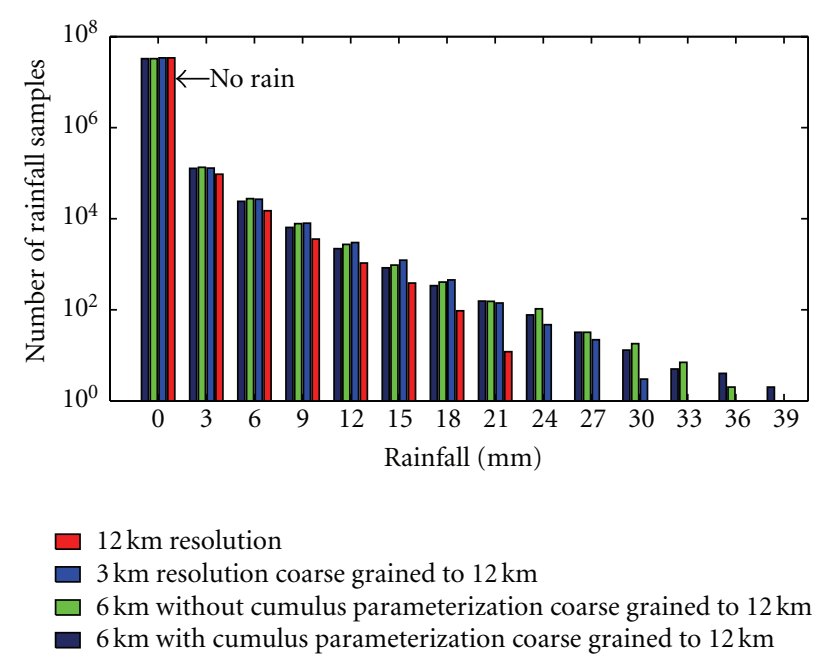

Figure 9: A comparative histogram with a $3 \mathrm{~mm}$ bin width for the rainfall from the $12 \mathrm{~km}, 6 \mathrm{~km}$ with and without parameterization, and $3 \mathrm{~km}$ runs. For the $6 \mathrm{~km}$ and $3 \mathrm{~km}$ runs, the data have been coarse grained to $12 \mathrm{~km}$ grid to facilitate a fair comparison to the $12 \mathrm{~km}$ runs.

Figure 2(a). This box covers a region with relatively flat topography and modest rainfall. Red and blue are the hourly rainfall and cumulative rainfall, respectively. The eight panels in that figure are from the runs with different resolutions and further separated into subgrid-scale (convective parameterization) and grid-scale rainfall, as detailed in the caption. What is noteworthy here is not the difference, but the similarity, among the eight panels. A significant rainfall event is usually picked up by all runs regardless of their horizontal resolutions (e.g., compare the last four panels). The difference is in the magnitude of rainfall. Also, the time series of the rainfall produced by subgrid-scale convective parameterization (RAINC) is similar to that produced by grid-scale processes (RAINNC), only that the latter has a larger amplitude (e.g., compare Figure (c) with Figure (d)). Although we only show the detailed time series for one winter, the characteristics described previously are shared by the simulations for the other 6 winters.

Figure 8 compares the hourly rainfall from the $12 \mathrm{~km}$ (blue dots) and $3 \mathrm{~km}$ (red line) runs for all 7 winter seasons (November-January) from 2003 to 2009 by stitching the seven 92-day runs together. Figure 8 (a) is for the average over box (i) and Figure 8(b) for box (ii) as marked in Figure 2(a). Figure $8(\mathrm{c})$ is the average over the entire Arizona domain. Unlike box (i) that covers the relatively flat southern part of Arizona, box (ii) is over the mountainous region in central Arizona with more intense rainfall. All three panels show that whenever there is a major rainfall event, it is usually picked up by both $12 \mathrm{~km}$ and $3 \mathrm{~km}$ runs. However, the rainfall from the $12 \mathrm{~km}$ run is systematically less intense than its counterpart from the $3 \mathrm{~km}$ run for the same event.

One can further quantify the differences among the $12 \mathrm{~km}, 6 \mathrm{~km}$, and $3 \mathrm{~km}$ runs by comparing their histograms of rainfall using the hourly data for all grid points in 


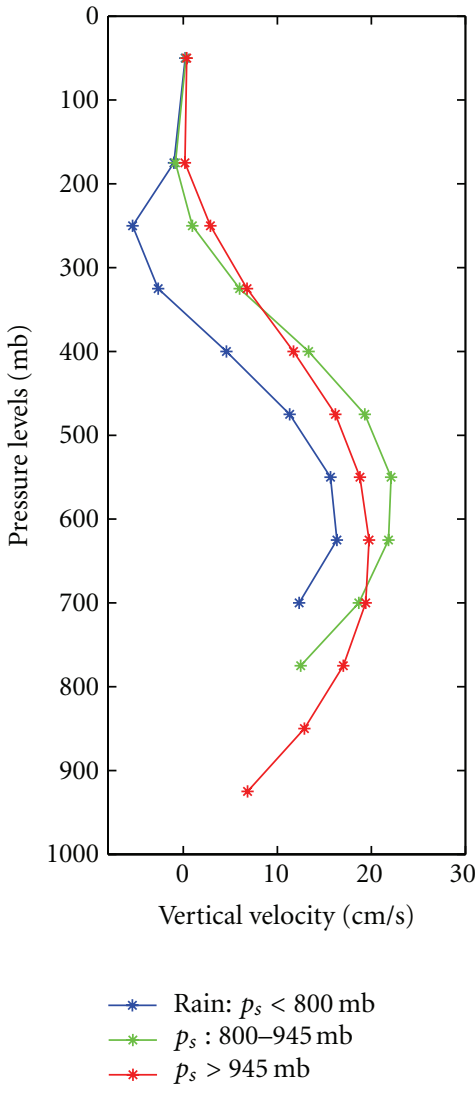

(a)

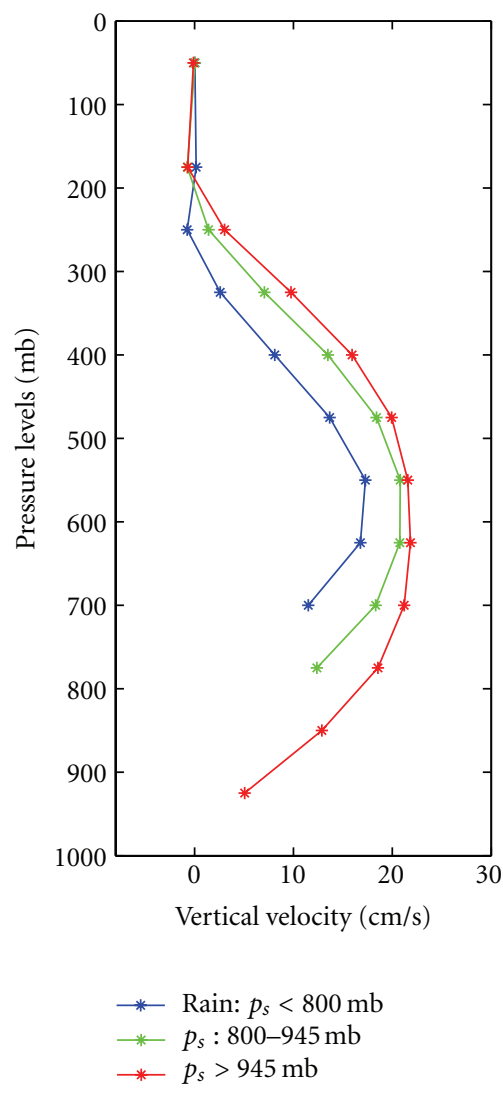

(b)

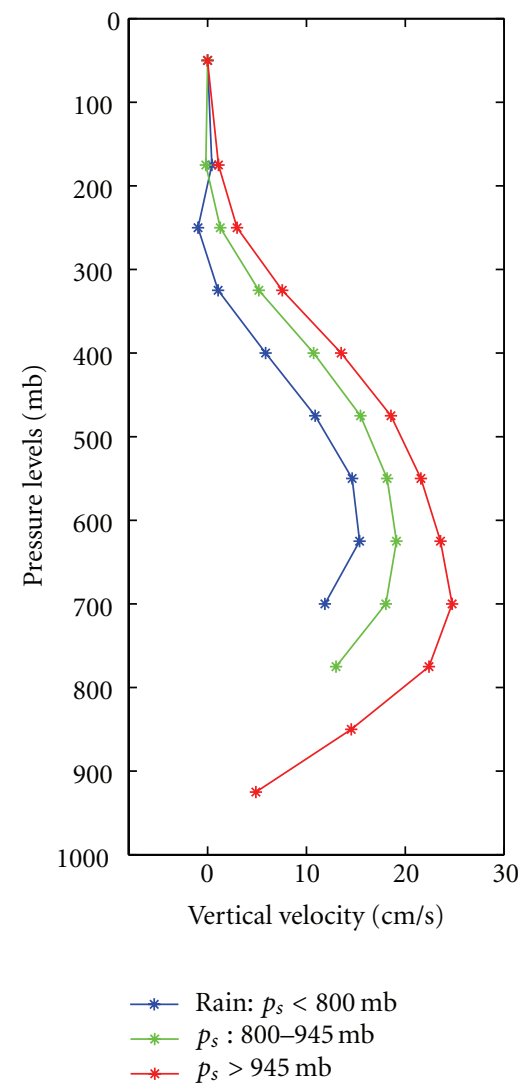

(c)

FIgURE 10: The averaged vertical profiles of vertical velocity (in $\mathrm{cm} / \mathrm{s}$ ) deduced from (a) $12 \mathrm{~km}$ runs, (b) $6 \mathrm{~km}$ runs with cumulus parameterization turned on, and (c) $3 \mathrm{~km}$ runs.

the innermost model domain over Arizona. For a fair comparison, we first merge $16(4 \times 4)$ grid boxes of the $3 \mathrm{~km}$ runs into a super box with dimension of $12 \mathrm{~km} \times 12 \mathrm{~km}$ (i.e., the same size as one grid box for the $12 \mathrm{~km}$ runs) and calculate the averaged rainfall for each super box. In doing so, we have about the same number of grid boxes (times the number of hours) from the $3 \mathrm{~km}$ and $12 \mathrm{~km}$ runs to construct the histograms. Similar approach is used to coarse grain $6 \mathrm{~km}$ to $12 \mathrm{~km}$ resolution. The comparison for all 4 major cases listed in Table 1 is shown in Figure 9 in a loglinear plot, using a bin width of $3 \mathrm{~mm}$ of rainfall. All 7 winters of simulations are used. (The left most bar is for the samples with no rain.) It is interesting to note that extreme rainfall events with hourly rainfall exceeding $21 \mathrm{~mm}$ over a $12 \mathrm{~km}$ $\times 12 \mathrm{~km}$ box are produced only by the $6 \mathrm{~km}$ and $3 \mathrm{~km}$ runs, while they are absent in the $12 \mathrm{~km}$ runs.

Given our finding here, it will certainly be useful if the high-frequency behavior of the simulated rainfall can be further validated with observation. We have not done so because the existing rainfall observations for Arizona do not have a spatial and temporal resolution comparable to our model simulations. (The PRISM data used for the model validation in Section 3.2 are only monthly mean.) This will be a very useful comparison to make if such high-resolution observations become available in the future.
3.4. Vertical Velocity. Since rainfall is closely related to vertical motion (either by convection or mechanical lifting), a further analysis of the variance of vertical velocity is performed to help understand the behavior of rainfall in our simulations. As a useful comparison of the vertical velocity field across the four major sets of simulations, we choose to focus on the standard deviation of vertical velocity at a mid-tropospheric level where vertical velocity is near its maximum. To help choosing this level, Figure 10 first illustrates the averaged vertical profile of vertical velocity from selected runs (one set each for 12, 6, and $3 \mathrm{~km}$ resolution). In order to meaningfully relate the vertical velocity to convection or rainfall, in Figure 10 only the vertical profiles over the grid points with hourly rainfall exceeding $2 \mathrm{~mm}$ are included for the averaging. Given the large variation of topography over Arizona, we further classified the grid points into three groups of low ( $p s>945 \mathrm{hPa})$, medium $(800 \mathrm{hPa}$ $<p s<945 \mathrm{hPa}$ ), and high surface elevation $(p s<800 \mathrm{hPa}$, where Ps is surface pressure), shown in Figure 10 in red, green, and blue, respectively. Each curve in Figure 10 is based on the statistics of hourly model output for the 7-winter runs. From Figure 10, the vertical profile of vertical velocity associated with rainfall generally has a unimodal structure with maximum at close to $625 \mathrm{hPa}$, a level we choose for a further analysis. 


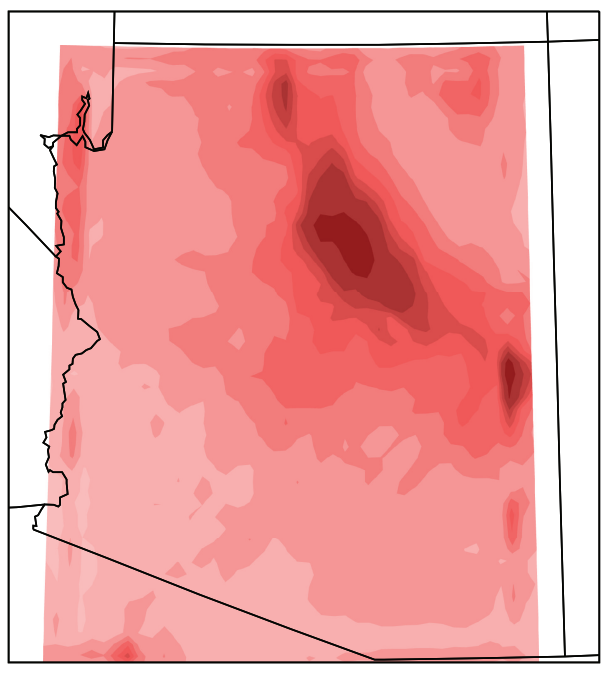

(a)
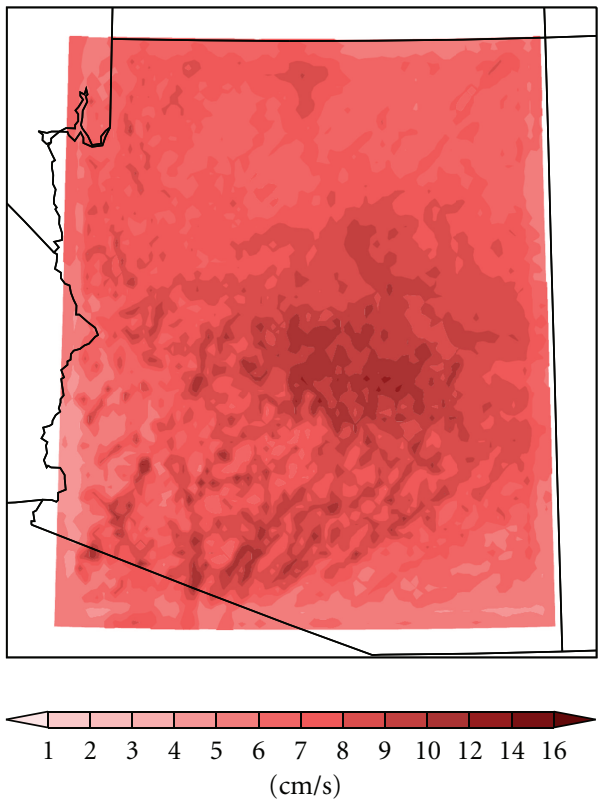

(c)

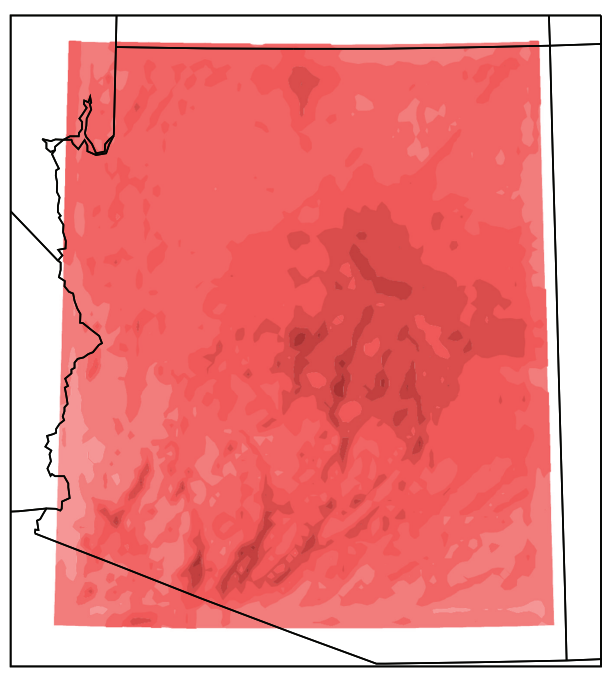

(b)
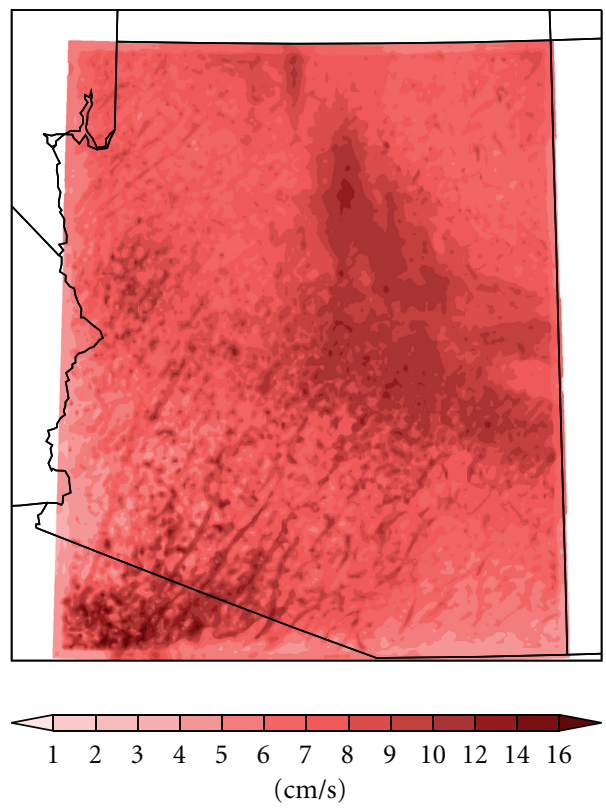

(d)

Figure 11: The standard deviation of vertical velocity at $625 \mathrm{hPa}$ level for (a) the $12 \mathrm{~km}$ runs, (b) the $6 \mathrm{~km}$ runs with cumulus parameterization turned on, (c) the $6 \mathrm{~km}$ runs with cumulus parameterization turned off, and (d) the $3 \mathrm{~km}$ runs. The color scale in cm/s is shown at bottom.

Figure 11 shows the standard deviation of vertical velocity at $625 \mathrm{hPa}$ level for the innermost domain, for the 4 major sets of runs with 12,6 , and $3 \mathrm{~km}$ resolution. At $12 \mathrm{~km}$ resolution, the maximum vertical velocity is mostly associated with large-scale topographic lifting over northern Arizona where the highest peaks of mountains in Arizona are located. Over there, most of the precipitation in winter is snow such that the maximum vertical velocity does not correspond to maximum liquid-form rainfall, which is located in central Arizona. For the two cases with $6 \mathrm{~km}$ and especially the case with $3 \mathrm{~km}$ resolution, we begin to see more fine structures of vertical velocity over the mountainous central Arizona and a hint of northeast-southwest-oriented streaks in southern Arizona. Those streaks are consistent with a similar structure in rainfall (see Figure 3(d)). They likely reflect the impact of fine topography on rainfall in this region. They become even more prominent in the $3 \mathrm{~km}$ run. The contrast between $3 \mathrm{~km}$ and $12 \mathrm{~km}$ runs in Figure 11 is significant. The aforementioned streaks in the $3 \mathrm{~km}$ runs are almost absent in the $12 \mathrm{~km}$ runs. The change in the characteristics of vertical velocity with resolution shown here is consistent with the changes in the intensity and patterns of rainfall in Figures 2 and 3. The maps in Figure 11 are based on the vertical velocity at original model grids, that is, the standard deviation in Figure 11(a) is on $12 \mathrm{~km}$ grid, and that in Figure 11(d) is on $3 \mathrm{~km}$ grid, and so on. However, even 
after coarse-graining the vertical velocity fields of the $6 \mathrm{~km}$ and $3 \mathrm{~km}$ runs to the $12 \mathrm{~km}$ grid, the qualitative differences among the 4 runs described previously remain true (not shown).

\section{Conclusions}

This study investigated the dependence of simulated rainfall on the model resolution in a series of climate downscaling experiments for Arizona for the cold season. It is found that the winter seasonal mean rainfall for different subdomains of Arizona increases substantially with the refinement of horizontal resolution from 12 to $6 \mathrm{~km}$. This conclusion holds regardless of whether the subgrid-scale cumulus parameterization is turned on or off in the $6 \mathrm{~km}$ run. At that resolution, twin experiments with convective scheme turned on and off produced approximately the same amount of rainfall for Arizona and its subdomains. When cumulus parameterization is turned off, the rainfall produced by gridscale processes increases to compensate for the absence of the contribution from (parameterized) subgrid-scale convection. A further refinement of the grid size to $3 \mathrm{~km}$ leads to relatively minor changes in the seasonal mean rainfall, indicating numerical convergence at this scale. However, a comparison with the observed seasonal mean rainfall from the PRISM data revealed that the rainfall simulated by the $6 \mathrm{~km}$ and $3 \mathrm{~km}$ runs is excessive, while that produced by the $12 \mathrm{~km}$ grid simulations is closer to observation. A plausible interpretation is that when WRF was first developed, the benchmark simulations used to fine tune the model against observation were run at a considerably coarser resolution than our 3 or $6 \mathrm{~km}$. Then, a greater deviation from observation can possibly be produced by the runs with a refined resolution if the parameterization schemes for rainfall in the model are not resolution independent.

This study also demonstrates the resolution dependence for the variance of vertical velocity, a variable that is intimately related to the processes (thermal convection and/or mechanical/topographic lifting) for rainfall production. At $12 \mathrm{~km}$ resolution, the maximum of the variance of vertical velocity is mainly associated with large-scale topographic lifting over the mountainous northern Arizona. With a refinement of grid size to $3 \mathrm{~km}$, streaks of high variance of vertical velocity begin to emerge in southern Arizona where mountains are shorter and smaller in horizontal scale. An analysis of the high frequency behavior of rainfall indicates that the $3 \mathrm{~km}$ runs produced significantly more extreme rainfall events within Arizona that are missing or muted in the $12 \mathrm{~km}$ runs. A verification of the simulated highfrequency statistics of rainfall with observation is more difficult due to a lack of long-term measurements with a sufficiently high resolution in both space and time. We will leave this important aspect to future work.

\section{Acknowledgments}

The authors acknowledge the support by NSF AGS-0934592, NOAA CPPA Program, and U.S. CRDF. They appreciate a useful conversation with Professor Chris Castro and useful comments from two reviewers.

\section{References}

[1] R. Seager, M. Ting, I. Held et al., "Model projections of an imminent transition to a more arid climate in southwestern North America," Science, vol. 316, no. 5828, pp. 1181-1184, 2007.

[2] A. Mariotti, N. Zeng, J. H. Yoon et al., "Mediterranean water cycle changes: transition to drier 21st century conditions in observations and CMIP3 simulations," Environmental Research Letters, vol. 3, no. 4, Article ID 044001, 2008.

[3] F. Giorgi, P. H. Whetton, R. G. Jones et al., "Emerging patterns of simulated regional climatic changes for the 21 st century due to anthropogenic forcings," Geophysical Research Letters, vol. 28, no. 17, pp. 3317-3320, 2001.

[4] L. R. Leung, Y. Qian, X. Bian, and A. Hunt, "Hydroclimate of the western United States based on observations and regional climate simulations of 1981-2000. Part I: seasonal statistics," Journal of Climate, vol. 16, no. 12, pp. 1892-1911, 2003.

[5] J. C. F. Lo, Z. L. Yang, and R. A. Pielke, "Assessment of three dynamical climate downscaling methods using the Weather Research and Forecasting (WRF) model," Journal of Geophysical Research D, vol. 113, no. 9, Article ID D09112, 2008.

[6] F. Giorgi and M. R. Marinucci, "An investigation of the sensitivity of simulated precipitation to model resolution and its implications for climate studies," Monthly Weather Review, vol. 124, no. 1, pp. 148-166, 1996.

[7] J. Kim, "A projection of the effects of the climate change induced by increased $\mathrm{CO} 2$ on extreme hydrologic events in the Western U.S," Climatic Change, vol. 68, no. 1-2, pp. 153-168, 2005.

[8] P. B. Duffy, R. W. Arritt, J. Coquard et al., "Simulations of present and future climates in the western United States with four nested regional climate models," Journal of Climate, vol. 19, no. 6, pp. 873-895, 2006.

[9] V. R. Duliè, Y. Zhang, and E. P. Salathe Jr, "Extreme precipitation and temperature over the U.S. Pacific Northwest: a comparison between observations, reanalysis data, and regional models," Journal of Climate, vol. 24, no. 7, pp. 19501964, 2011.

[10] T. R. Knutson, J. J. Sirutis, S. T. Garner, I. M. Held, and R. E. Tuleya, "Simulation of the recent multidecadal increase of Atlantic hurricane activity using an $18-\mathrm{km}$-grid regional model," Bulletin of the American Meteorological Society, vol. 88, no. 10, pp. 1549-1565, 2007.

[11] B. Rockel, C. L. Castro, R. A. Pielke, H. von Storch, and G. Leoncini, "Dynamical downscaling: assessment of model system dependent retained and added variability for two different regional climate models," Journal of Geophysical Research D, vol. 113, no. 21, Article ID D21107, 2008.

[12] P. Caldwell, H. N. S. Chin, D. C. Bader, and G. Bala, "Evaluation of a WRF dynamical downscaling simulation over California," Climatic Change, vol. 95, no. 3-4, pp. 499-521, 2009.

[13] M. S. Bukovsky and D. J. Karoly, "Precipitation simulations using WRF as a nested regional climate model," Journal of Applied Meteorology and Climatology, vol. 48, no. 10, pp. 21522159, 2009.

[14] R. Urrutia and M. Vuille, "Climate change projections for the tropical Andes using a regional climate model: temperature 
and precipitation simulations for the end of the 21st century," Journal of Geophysical Research D, vol. 114, no. 2, Article ID D02108, 2009.

[15] S. A. Rauscher, E. Coppola, C. Piani, and F. Giorgi, "Resolution effects on regional climate model simulations of seasonal precipitation over Europe," Climate Dynamics, vol. 35, no. 4, pp. $685-711,2010$.

[16] E. K. Gilliland and C. M. Rowe, "A comparison of cumulus parameterization scheme in the WRF model," in Proceedings of the 21th Conference on Hydrology, San Antonio, Tex, USA, 2007.

[17] J. Mercader, B. Codina, A. Sairouni, and J. Cunillera, "Sensitivity of precipitation forecasts to cumulus parameterizations in Catalonia (NE Spain)," in Proceedings of the 8th WRF Users' Workshop, National Center for Atmospheric Research, Boulder, Colo, USA, June 2007.

[18] W. D. Sellers, Arizona Climate, The University of Arizona Press, Tucson, Arizona, 1960.

[19] C. A. Woodhouse, "Winter climate and atmospheric circulation patterns in the Sonoran Desert Region, USA," International Journal of Climatology, vol. 17, no. 8, pp. 859-873, 1997.

[20] P. R. Sheppard, A. C. Comrie, G. D. Packin, K. Angersbach, and M. K. Hughes, "The climate of the US Southwest," Climate Research, vol. 21, no. 3, pp. 219-238, 2002.

[21] J. C. Collier and G. J. Zhang, "Effects of increased horizontal resolution on simulation of the North American monsoon in the NCAR CAM3: an evaluation based on surface, satellite, and reanalysis data," Journal of Climate, vol. 20, no. 9, pp. 1843-1861, 2007.

[22] J.-L. Lin, B. E. Mapes, K. M. Weickmann et al., "North American monsoon and convectively coupled equatorial waves simulated by IPCC AR4 coupled GCMs," Journal of Climate, vol. 21, no. 12, pp. 2919-2937, 2008.

[23] W. C. Skamarock, J. B. Klemp, J. Dudhia et al., "A description of the advanced research WRF version 3," NCAR Technical Note NCAR/TN-4751STR, 2008.

[24] J. S. Kain and J. Kain, "The Kain-Fritsch convective parameterization: an update," Journal of Applied Meteorology, vol. 43, no. 1, pp. 170-181, 2004.

[25] R. A. Bryson and F. K. Hare, The Climates of North America, Elsevier, New York, NY, USA, 1974.

[26] C. Daly, T. G. F. Kittel, A. McNab et al., "Development of a 103year high-resolution climate data set for the conterminous United States," in Proceedings of the 12th AMS Conference on Applied Climatology, pp. 249-252, American Meteorological Society, Ashville, NC, USA, May 2000.

[27] W. P. Gibson, C. Daly, T. Kittel et al., "Development of a 103year high-resolution climate data set for the conterminous United States," in Proceedings of the 13th AMS Conference on Applied Climatology, pp. 181-183, American Meteorological Society, Portland, Ore, USA, May 2002. 

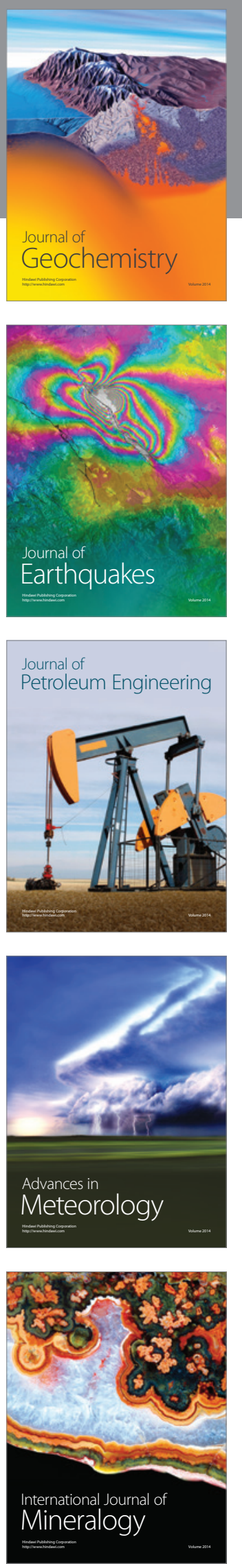
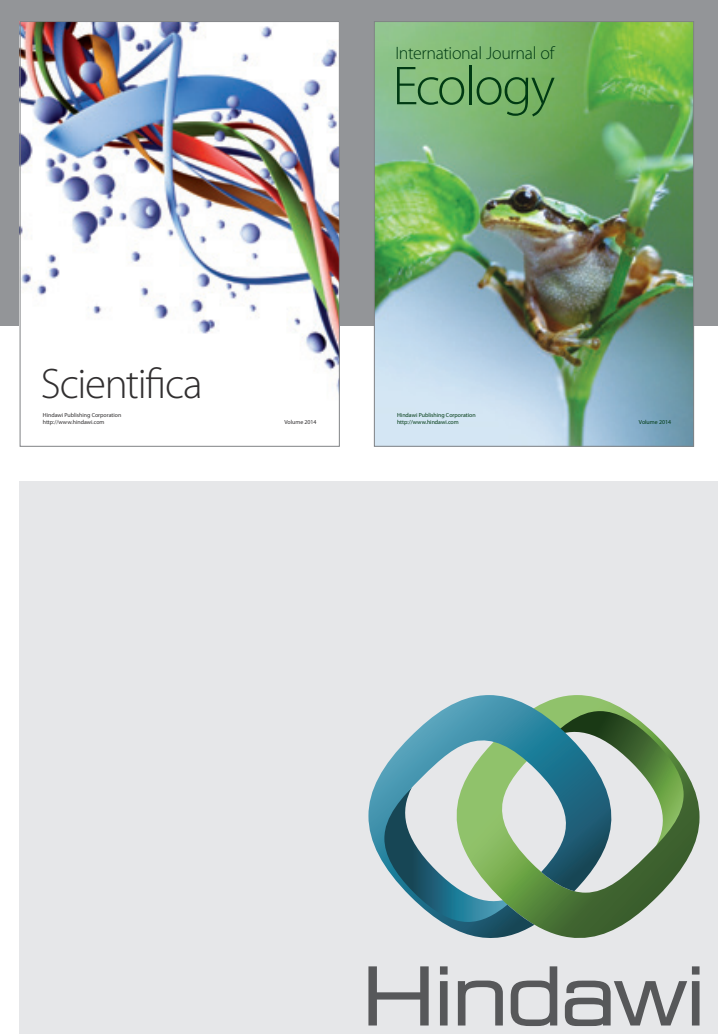

Submit your manuscripts at http://www.hindawi.com
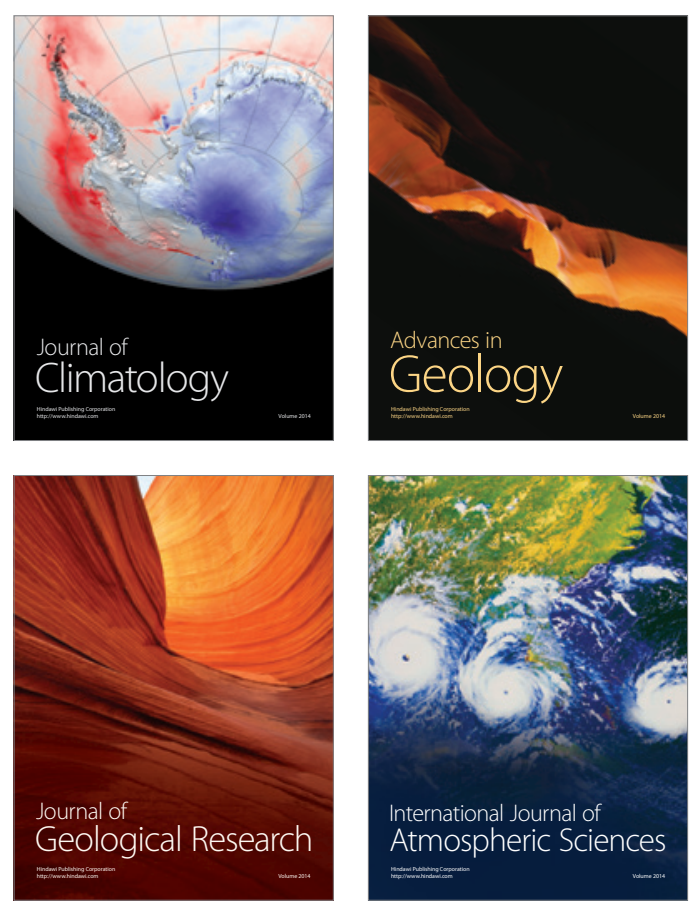
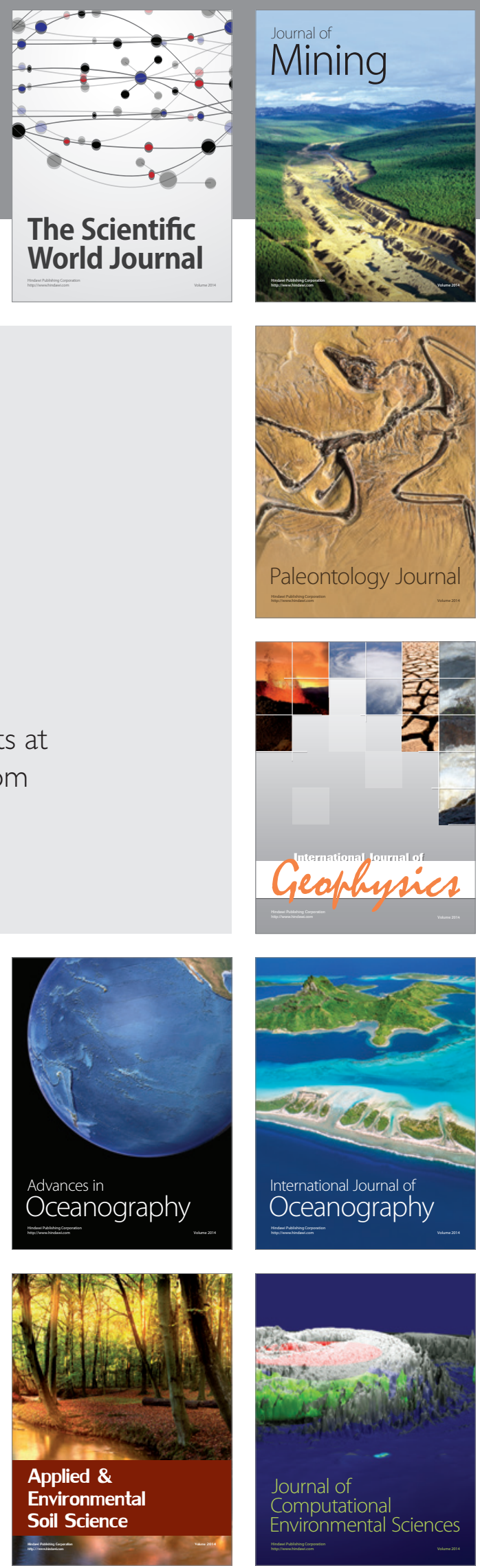